\title{
Factors influencing dairy calf and replacement heifer mortality in France
}

\author{
D. Raboisson, ${ }^{*} \dagger \ddagger^{1}$ E. Maigne, $\dagger$ P. Sans,§\# G. Allaire, $\dagger$ and E. Cahuzac $†$ \\ *Université de Toulouse, Institut National Polytechnique (INP), Ecole Nationale Vétérinaire de Toulouse (ENVT), UMR1225, \\ Interaction Hôte Agent Pathogène (IHAP), 31076, Toulouse, France \\ †INRA, US0685, Observatoire du Développement Durable (ODR), 31326, Auzeville, France \\ †INRA, UMR1225, IHAP, 31076, Toulouse, France \\ §Université de Toulouse, INP, ENVT, Toulouse, France \\ \#INRA, UR1303, Alimentation et Sciences Sociales (ALISS), 94205, Ivry-sur-Seine, France
}

\section{ABSTRACT}

Herd-level risk factors for dairy calf and heifer mortality in France were identified by calculating herd-level variables (including mortality risk or rate) using the National Bovine Identification Database (2005 and 2006). Eleven dairy production areas representing different livestock systems were also included. Statistical analyses were based on a probit model (mortality risk or rate $=0$ or $>0$ ) and a linear model (mortality risk or rate $>0$ ) corrected by the sample bias Heckman method. The same associations were reported for 2005 and 2006. The mortality risks or rates for calves and heifers were positively associated with the proportion of purchased cows or being a Milk Control Program member and negatively associated with adhering to the Good Breeding Practices charter and having an autumn calving peak. The associations between mortality and the breeds or the production areas were positive or negative, depending on the classes of animal. Mortality and having a beef herd in addition to the dairy herd were negatively associated for noncrossed birth to 2-d-old calves, noncrossed 3-d- to 1-mo-old calves, and 3-d- to 1-mo-old heifers. Having a beef herd probably provides specific know-how related to newborn and young calf management that makes it easier to attain low mortality in pure-breed dairy calves. The proportion of males born was positively associated with mortality for the birth to 2-d-old calves (all classes) and for the 3-dto 1-mo-old beef-crossed calves, but negatively for all classes of heifers. This indicates that heifer management was improved when the availability of newborn heifers decreased, resulting in low mortality. This lower mortality is apparent for all classes of heifers present on the farm during the year when the proportion of males was low, and demonstrates an anticipatory effect. In conclusion, this study shows that the presence of a beef herd in addition to the dairy herd within a farm is

Received March 24, 2013.

Accepted September 27, 2013.

${ }^{1}$ Corresponding author: d.raboisson@envt.fr associated with decreased dairy calf mortality. It also shows that heifer mortality decreases when the proportion of heifers born decreased. These determinants of dairy calf and heifer mortality are of great importance for farmer advisors, the dairy industry, and the political decision makers.

Key words: dairy calf mortality, France, herd-level factor, farm environment

\section{INTRODUCTION}

Calf and heifer mortality represents economic losses to the dairy industry as well as being a welfare issue (Meyer et al., 2001; Ortiz-Pelaez et al., 2008). This is all the more important in that a continuous increase in the frequency of stillbirths has been reported in many countries over the last decade (Meyer et al., 2001; Berglund et al., 2003; Steinbock et al., 2003). The mortality rates in French dairy calves and heifers, reported in a companion paper, were low to moderate, compared with other international results (Raboisson et al., 2013). In 2005 to 2006, the overall French 0- to 2-d-old and 3-d- to 1-mo-old calf mortality rates were around 6.7 and $5.7 \%$, respectively. The heifer 3 -d- to 1 -mo-old, 1- to 6-mo-old, and 6-mo-old to first calving mortality rates were $4.5,3.1$, and $4.1 \%$, respectively (Raboisson et al., 2013). The variations between mortality rates are, however, large.

Many studies have identified animal- or herd-level risk factors of dairy calf and heifer mortality, such as dystocia, sex, twin, parity of the dam, herd size, and season (Wells et al., 1996, 1997; Meyer et al., 2000; Lombard et al., 2007; Stull et al., 2008). Calf management procedures have also been associated with the risk of mortality. Among them, one of the most important risk factors of mortality (and morbidity) is failure of passive transfer of antibodies via the colostrum (Rea et al., 1996; Donovan et al., 1998; Beam et al., 2009), with effects on heifer mortality up to 8 to $10 \mathrm{wk}$ of age (Tyler et al., 1998) or longer (Donovan et al., 1998). In one study in which $8.2 \%$ of the heifers died before 
16 wk of age, the baseline mortality rate was $5.0 \%$ and the mortality rate due to inadequate passive transfer was $3.2 \%$ (Tyler et al., 1999). Recent investigations have revealed associations between factors related to the farmer's behavior or working context and calf mortality. For instance, having "flexible time" appeared crucial for the management of crises and was associated with reduced calf morbidity and mortality (Vaarst and Sorensen, 2009).

Many dairy farms throughout the world have less than or around 100 cows and the farmers have to manage a wide range of tasks within the farm. Few studies dealing with the risk factors of cattle mortality have taken such constraints into account and many only focus on 1 class of animal (for instance, perinatal calf mortality; Meyer et al., 2001; Silva del Río et al., 2007; Gundelach et al., 2009; Johanson et al., 2011). However, the effects of management practices and farmer behavior can be better understood by focusing on mortality risk factors in several classes of animal simultaneously. France constitutes a good example for such studies, thanks to its broad diversity of livestock production (i.e., dairy, beef or fattening, mountains or plains, generic or specificquality production; Rouquette and Pflimlin, 1995; Sarzeaud et al., 2008). This country offers the possibility of identifying the combinations of factors, including the farmer's know-how associated with low mortality. The first aim of the present study was to identify new herdlevel factors influencing dairy calf and heifer mortality and the second aim was to determine whether some risk factors could have opposing effects on mortality, depending on the class of animal studied.

\section{MATERIALS AND METHODS}

\section{Data Sets}

The characteristics of the National Bovine Identification Database have already been described in detail (Raboisson et al., 2011). Briefly, this database contains routine records for individual farms and animals. All births, deaths, purchases, and sales, as well as the date of the event, are recorded by farmers in the National Bovine Identification Database. This is mandatory and official controls are frequently carried out with potential high penalties. For this study, the animals within each farm were sorted and associated with a dairy, beef (suckler cows), or fattening (bulls, steers, or veal calves) herd. Herds with less than 6 cows per year were excluded. All data were geolocated at the municipal level. There are 3,600 municipalities in France, with a mean area of $15 \mathrm{~km}^{2}$. Other data sets used were the farms registered as adhering to the Good Breeding Practices charter (a voluntary program that includes constraints on management, feeding, breeding, and welfare), herds in the Milk Control Program (registration of milk production and milk composition plus herd management recommendations), and herds in dairy production areas, as previously described (Raboisson et al., 2011).

\section{Variables}

Mortality Risk and Rate. The mortality risks and rates were calculated annually (2005 and 2006), for each group of animals within each herd. The 0- to 2-d mortality risk was the number of deaths occurring between birth and $2 \mathrm{~d}$ of age divided by the number of calves born (males and females). This value was calculated for the pure dairy breed (noncrossed) and the beef-crossed dairy calves. The numerators for the male and female 3 -d- to 1-mo-old calf, the 3 -d- to 1-mo-old heifer, the 1 - to 6 -mo-old heifer, and the 6-mo-old to first-calving heifer mortality rates were the number of deaths occurring during the period. The denominators were the number of male and female calf-months, heifer-months, heifer-5 mo, and heifer-years, respectively. Heifer-5 mo equaled 1 if the heifer stayed for $5 \mathrm{mo}$ and 0.5 if it stayed for 2.5 mo. For the 3-d- to 1-mo-old calf mortality, distinctions were also made between pure breed and beef-crossed dairy calves.

Herd-Level and Contextual Factors. Most of the herd-level factors used in the present study have already been described in detail (Raboisson et al., 2011). Variables included the annual number of cow-years, the predominant breed of the herd $(>75 \%$ of the dairy cows in the herd), the average calving interval and the farm type (specialized in dairy production, dairy and beef production, or dairy and fattening production on the same farm). The variable "purchase of cows from other farms" was defined as the number of purchased cows divided by the number of cow-years, transformed into a categorical factor (no purchase, low purchase, or high purchase), low and high purchase being defined as the $75 \%$ quartile of the purchase percentage (i.e., 27 and $19 \%$ for 2005 and 2006, respectively). The annual proportion of primiparous cows was the number of first-calving cows divided by the overall number of calvings in the year. The culling rate was the number of dairy cows sold, death excluded, divided by the number of cow-years, irrespective of the in-milk or dry status, or of the reasons for removal. The variable "autumn calving peak" was defined as the calving peak $(>35 \%$ of the annual calvings occurred during 3 mo) between July and November. It was designed to make use of the inclination of farmers to produce milk during the bestpaid period of the year. Being a Milk Control Program member or adhering to the Good Breeding Practices charter was defined once for the 2-yr period. 
Table 1. Descriptive statistics for continuous variables in 2005 and 2006

\begin{tabular}{lcccccc}
\hline Variable & Year & Minimum & Maximum & Mean & SD & Median \\
\hline Number of cow-years $^{1}$ & 2005 & 5.1 & 404.2 & 37.7 & 20.3 & 34.4 \\
& 2006 & 5.1 & 421.1 & 38.7 & 20.7 & 35.2 \\
First-calving cow proportion, \% & 2005 & 0.0 & 100 & 28.6 & 12.7 & 30.0 \\
& 2006 & 0.0 & 100 & 28.0 & 12.9 & 29.4 \\
Percentage of beef-crossed calves, \% & 2005 & 0.0 & 100 & 23.4 & 30.6 & 8.8 \\
& 2006 & 0.0 & 100 & 22.8 & 30.1 & 7.8 \\
Percentage of males born, \% & 2005 & 5.6 & 94.7 & 50.9 & 10.6 & 50.9 \\
& 2006 & 5.3 & 95.8 & 51.0 & 10.5 & 51.1 \\
\hline
\end{tabular}

${ }^{1}$ The number of cow-years equaled the sum of all the days and all the cows divided by 365 .

Two other herd-level variables were included in the present study. The percentage of beef-crossed calves was defined as the number of beef-crossed calves born from dairy cows divided by the overall number of calves born from dairy cows. The percentages of males in relation to all calves born from dairy cows were calculated annually.

The 2 contextual factors, notably the cattle density (in livestock unit $/ \mathrm{km}^{2}$ ) and the inhabitant density (no./ $\mathrm{km}^{2}$ ), have been described previously (Raboisson et al., 2011). The 11 dairy production areas of France (Raboisson et al., 2011) approximately overlap the French livestock systems (Rouquette and Pflimlin, 1995; Sarzeaud et al., 2008).

\section{Statistical Analysis}

Data were analyzed using $\mathrm{R}$ (version 2.10.1; R Foundation for Statistical Computing, Vienna, Austria). The models used have been described in detail elsewhere (Raboisson et al., 2011). First, the probability of having at least 1 death was analyzed by probit regression. Second, the mortality risk or rate was subjected to a linear regression using the Heckman correction and the results of the previous probit regression. The models were applied to the different classes of animal separately for 2005 and 2006. For each model, those variables which were not significant were removed and the results from the final multifactorial models are reported.

The results of the probit regression were expressed as odds ratios. For linear regression modeling, they were expressed as the percentages change when the quantitative variables were changed by 1 unit or compared with a reference class for the categorical variables (UCLA, 2012).

All possible 2-factor interactions with all the main effects were included (one by one) in the model. Depending on the coefficient of the interaction and on the Akaike information criterion of the model, the interaction, even if significant, could be removed from the model and interpreted as a significant interaction without any biological importance.

\section{RESULTS}

The descriptive statistics for the mortality risks or rates per class of animal and the odds ratios of mortality per breed, sex, and dairy production areas have been described in a companion paper (Raboisson et al., 2013). The descriptive statistics for the variables used in the models are reported in Tables 1 and 2 .

The same associations $(P<0.01)$ and very similar coefficients were obtained for 2005 and 2006 and only the final multifactorial models for 2005 are reported (Tables 3 to 6 ). The culling rate, the average calving interval, and the 2 contextual variables (municipal cattle and inhabitant densities) were not significantly associated with the mortality risk or rate in any of the models. These variables were, therefore, removed from the models. Most of the significant interactions were considered as non-biologically relevant. Their associations with mortality were very weak.

For the great majority of variables and for all models, the same associations between the variables and mortality (whether positive or negative) were reported for the probit (having at least 1 death) and linear models (mortality risk or rate, if $>0$ ). Some variables were deleted from the probit or linear models, when nonsignificant.

Whatever the class of animal considered, the models showed the same associations between mortality and the herd size (positive), purchasing dairy cows (positive), having a calving peak in autumn (negative), being a Milk Control Program member (positive), and adhering to the Good Breeding Practices charter (negative; Tables 3 to 6 ). Nevertheless, there were 2 exceptions. One was the negative association between being a Milk Control Program member and heifer mortality between 6 mo of age and the first calving. The second was the negative association between adhering to the Good Breeding Practices charter and the 0-d- to 2-d-old calf mortality.

Having a beef or fattening herd in addition to the dairy herd was associated with decreased mortality for the noncrossed 0- to 2-d-old and the noncrossed 2-d- to 
Table 2. Descriptive statistics for categorical variables in 2005 and 2006

\begin{tabular}{|c|c|c|}
\hline \multirow[b]{2}{*}{ Variable } & \multicolumn{2}{|c|}{ Number of farms } \\
\hline & 2005 & 2006 \\
\hline \multicolumn{3}{|l|}{ Predominant breed } \\
\hline Holstein & 57,496 & 55,041 \\
\hline Montbéliarde & 16,034 & 15,408 \\
\hline Normande & 9,024 & 8,470 \\
\hline No predominant & 16,170 & 15,402 \\
\hline Other breeds & 2,721 & 2,633 \\
\hline \multicolumn{3}{|l|}{ Farm type } \\
\hline Dairy & 48,220 & 45,507 \\
\hline Dairy and beef & 17,625 & 17,313 \\
\hline Dairy and fattening & 35,624 & 34,144 \\
\hline \multicolumn{3}{|c|}{ Purchased cow proportion } \\
\hline No purchase & 75,585 & 71,571 \\
\hline Low purchase & 23,386 & 21,157 \\
\hline High purchase & 2,474 & 4,226 \\
\hline \multicolumn{3}{|c|}{ Milk Control Program member } \\
\hline No & 38,941 & 36,196 \\
\hline Yes & 62,504 & 60,758 \\
\hline \multicolumn{3}{|c|}{ Good Breeding Practices member } \\
\hline No & 39,090 & 35,353 \\
\hline Yes & 62,355 & 61,601 \\
\hline \multicolumn{3}{|l|}{ Autumn calving peak } \\
\hline No & 79,116 & 76,090 \\
\hline Yes & 22,329 & 20,864 \\
\hline \multicolumn{3}{|l|}{ Dairy production area } \\
\hline 1 (Grand-Ouest) & 31,662 & 30,263 \\
\hline 2 (Normandie) & 14,400 & 13,701 \\
\hline 3 (Nord) & 9,348 & 8,899 \\
\hline 4 (Est) & 8,130 & 7,828 \\
\hline 5 (Centre) & 1,697 & 1,597 \\
\hline 6 (Poitou) & 2,905 & 2,755 \\
\hline 7 (Massif Central) & 8,628 & 8,320 \\
\hline 8 (Rhône-Alpes) & 7,617 & 7,204 \\
\hline 9 (Sud-Ouest) & 9,442 & 9,010 \\
\hline 10 (Franche-Conté) & 5,226 & 5,077 \\
\hline 11 (Savoie) & 2,390 & 2,316 \\
\hline
\end{tabular}

1-mo-old calves (Tables 3 and 4), as well as for the 2-dto 1-mo-old heifers (except for fattening; Table 5). The association was yet positive for the beef-crossed 0 - to 2-d-old and the beef-crossed 2-d- to 1-mo-old calves (Tables 3 and 5) and for heifers $>1$ mo of age (Table 6 ). The proportion of primiparous cows was positively associated with the mortalities of 0- to 2-d-old (Table 3) and beef-crossed 3-d- to 1-mo-old calves (Table 4), whereas a negative association was reported for noncrossed 3-d- to 1-mo-old calves (Table 4) and heifers (Tables 5 and 6 ). When significant, the percentage of beef-crossed calves was negatively associated with mortality risk or rate for all classes of animal, except for beef-crossed calves (Tables 3 to 6 ). The percentage of males born was positively associated with the mortality of 0 - to 2-d-old calves (all classes) and noncrossed 3-dto 1-mo-old calves, whereas no association was found for beef-crossed 3-d- to 1-mo-old calves (Tables 3 and 4). A negative association with mortality was reported for all classes of heifers (Tables 5 and 6). The associations between the dairy production areas or breeds and the mortality per class of animal are described in detail in Tables 3 to 6 and summarized in Table 7 .

\section{DISCUSSION}

\section{Database, Statistical Methods, and Previously Reported Associations}

The data in the National Bovine Identification Database are very accurate (Raboisson et al., 2011, 2013). The age classes used in the present study are in accordance with previous studies (Donovan et al., 1998; Meyer et al., 2001; Gulliksen et al., 2009; Johanson et al., 2011), even though the classes were often broader in the other studies.

The observed positive association between the proportion of primiparous cows and mortality in 0 - to 2 -dold calves or in 3-d- to 1-mo-old beef-crossed calves is in accordance with previous results (Meyer et al., 2001). This might be due to the higher probability of dystocia for primiparous cows (Meyer et al., 2000; Bicalho et 
Table 3. Mortality of noncrossed and beef-crossed 0 - to 2 -d-old dairy calves ${ }^{1}$

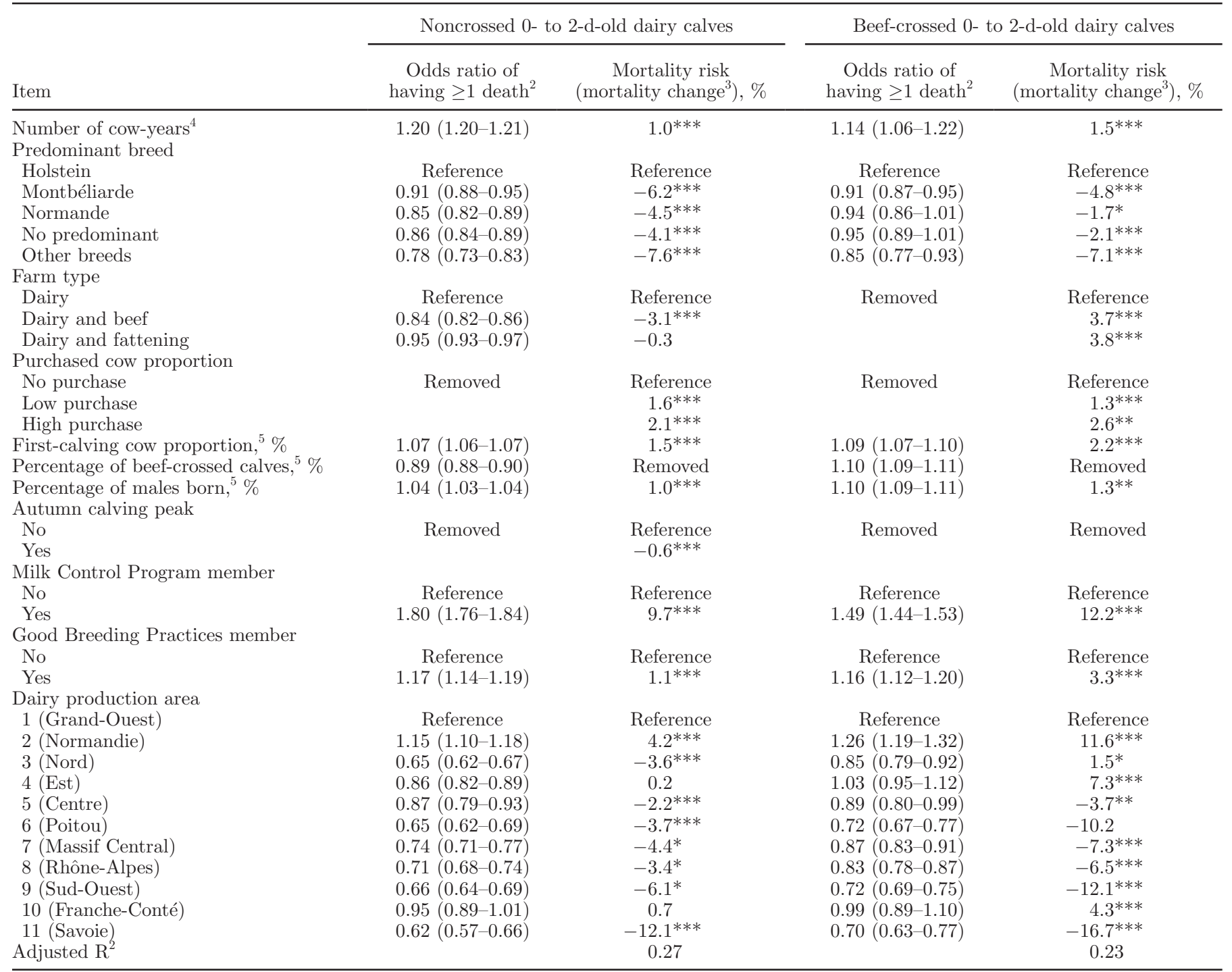

${ }^{1}$ Reference $=$ for the considered variable, class used as reference; removed $=$ the variable was removed from the model because it was not significant.

${ }^{2}$ The $95 \%$ CI is given in parentheses.

${ }^{3}$ The results were expressed in mortality change (\%). For instance, having a beef herd in addition to a dairy herd (farm type $=$ dairy and beef) was associated with a mortality risk change of $-3.1 \%$ for the noncrossed 0 - to 2 -d-old dairy calves, and with a mortality risk change of $+3.7 \%$ for the beef-crossed 0 - to 2-d-old dairy calves, compared with not having a beef herd in addition to a dairy herd (farm type = dairy; reference class). ${ }^{4}$ For an increase in herd size of 10 cow-years; the number of cow-years equaled the sum of all the days and all the cows divided by 365.

${ }^{5}$ For an increase of $10 \%$.

${ }^{*} P<0.05 ;{ }^{* *} P<0.01 ; * * * P<0.001$.

al., 2007; Lombard et al., 2007; Linden et al., 2009). In contrast, the negative association between heifer mortality and the proportion of primiparous cows could be related to differences in the replacement policy between herds. Herds with low heifer mortality were more likely to have a high proportion of primiparous cows.

Herd size and the purchasing of dairy cows were positively associated with calf and heifer mortality for all classes of animal, in accordance with previous results
(Wells et al., 1997; Gulliksen et al., 2009). The observed associations between mortality and being a member of the Milk Control Program (positive), adhering to the Good Breeding Practices charter (negative), and having a calving peak in autumn (negative) have already been reported for dairy cows in France (Raboisson et al., 2011). The positive association between adherence to the Good Breeding Practices charter and the 0- to 2-d-old calf mortality remains unexplained. 
Table 4. Mortality of noncrossed and beef-crossed 3-d- to 1-mo-old dairy calves ${ }^{1}$

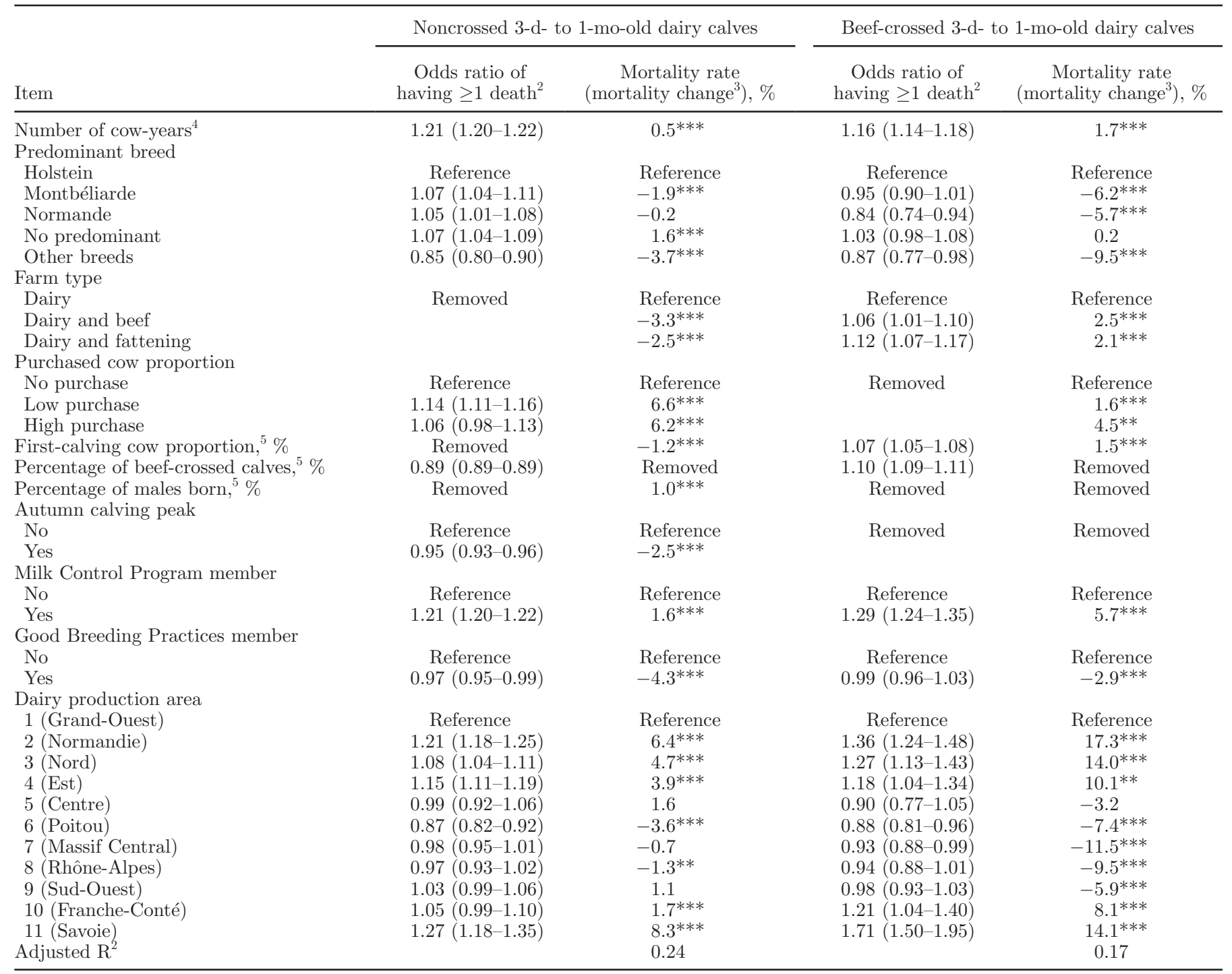

${ }^{1}$ Reference $=$ for the considered variable, class used as reference; removed $=$ the variable was removed from the model because it was not significant.

${ }^{2}$ The $95 \%$ CI is given in parentheses.

${ }^{3}$ The results were expressed in mortality change (\%). For instance, having a beef herd in addition to a dairy herd (farm type = dairy and beef) was associated with a mortality rate change of $-3.3 \%$, for the noncrossed 3 -d- to 1-mo-old dairy calves, compared with not having a beef herd in addition to a dairy herd (farm type = dairy; reference class).

${ }^{4}$ For an increase in herd size of 10 cow-years; the number of cow-years equaled the sum of all the days and all the cows divided by 365 .

${ }^{5}$ For an increase of $10 \%$.

$* * P<0.01 ; * * * P<0.001$

\section{New Findings}

The present results show that the mortality of noncrossed 0- to 2-d-old and of noncrossed 2-d- to 1-mo-old dairy calves is negatively associated with having a beef herd in addition to the dairy herd within the farm. The direction of the relationship remains unknown. This negative association might indicate that dairy farmers with low calf mortality are more likely to have a beef herd in addition to their dairy herd compared with those with high calf mortality. It might also indicate that having a beef herd is associated with better technical management of dairy calves (reduced mortality). Whatever the direction of the relationship, the only logical mechanism we found is that farmers with a beef herd in addition to a dairy herd are technically more competent in young calf management (including calving) than farmers specialized in dairy production. This is highly suggested by the frequency of difficult calving and the greater need for nursing in French beef breeds 
Table 5. Mortality of 3-d- to 1-mo-old dairy heifers ${ }^{1}$

\begin{tabular}{|c|c|c|}
\hline \multirow[b]{2}{*}{ Item } & \multicolumn{2}{|c|}{ 3-d- to 1-mo-old dairy heifers } \\
\hline & $\begin{array}{c}\text { Odds ratio of } \\
\text { having } \geq 1 \text { death }^{2}\end{array}$ & $\begin{array}{c}\text { Mortality rate } \\
\left(\text { mortality change }^{3}\right), \%\end{array}$ \\
\hline Number of cow-years ${ }^{4}$ & $1.17(1.16-1.18)$ & $1.7^{* * *}$ \\
\hline \multicolumn{3}{|l|}{ Predominant breed } \\
\hline Holstein & Reference & Reference \\
\hline Montbéliarde & $1.07(1.02-1.12)$ & $0.9^{*}$ \\
\hline Normande & $1.09(1.05-1.13)$ & $2.8^{* * *}$ \\
\hline No predominant & $1.06(1.03-1.09)$ & $3.3^{* * *}$ \\
\hline Other breeds & $0.86(0.80-0.93)$ & $-4.2^{* * *}$ \\
\hline \multicolumn{3}{|l|}{ Farm type } \\
\hline Dairy & Reference & Reference \\
\hline Dairy and beef & $0.96(0.93-0.99)$ & $-1.1^{* * *}$ \\
\hline Dairy and fattening & $1.04(1.01-1.06)$ & $2.1^{* * *}$ \\
\hline \multicolumn{3}{|l|}{ Purchased cow proportion } \\
\hline No purchase & Reference & Reference \\
\hline Low purchase & $1.16(1.13-1.19)$ & $7.2^{* * *}$ \\
\hline High purchase & $1.09(1.01-1.18)$ & $6.9^{*}$ \\
\hline First-calving cow proportion, ${ }^{5} \%$ & Removed & $-1.0^{* * *}$ \\
\hline Percentage of beef-crossed calves, ${ }^{5} \%$ & $0.89(0.87-0.90)$ & $-1.7^{* * *}$ \\
\hline Percentage of males born, ${ }^{5} \%$ & $0.89(0.89-0.89)$ & $-1.0^{* *}$ \\
\hline \multicolumn{3}{|l|}{ Autumn calving peak } \\
\hline No & Reference & Reference \\
\hline Yes & $0.92(0.90-0.94)$ & $-3.7^{* * *}$ \\
\hline \multicolumn{3}{|l|}{ Milk Control Program member } \\
\hline No & Reference & Reference \\
\hline Yes & $1.10(1.07-1.13)$ & $1.1^{* * *}$ \\
\hline \multicolumn{3}{|l|}{ Good Breeding Practices member } \\
\hline No & Reference & Reference \\
\hline Yes & $0.94(0.92-0.96)$ & $-4.8^{* * *}$ \\
\hline \multicolumn{3}{|l|}{ Dairy production area } \\
\hline 1 (Grand-Ouest) & Reference & Reference \\
\hline 2 (Normandie) & $1.20(1.16-1.24)$ & $8.9^{* * *}$ \\
\hline 3 (Nord) & $1.08(1.04-1.12)$ & $5.7^{* * *}$ \\
\hline 4 (Est) & $1.13(1.14-1.22)$ & $7.8^{* * *}$ \\
\hline 5 (Centre) & $1.05(0.97-1.13)$ & 2.2 \\
\hline 6 (Poitou) & $0.94(0.88-1.01)$ & -2.1 \\
\hline 7 (Massif Central) & $1.06(1.01-1.11)$ & $2.4^{* *}$ \\
\hline 8 (Rhône-Alpes) & $1.01(0.95-1.05)$ & 0.9 \\
\hline 9 (Sud-Ouest) & $1.07(1.02-1.12)$ & $4.4^{* * *}$ \\
\hline 10 (Franche-Conté) & $1.12(1.05-1.18)$ & $3.6^{* * *}$ \\
\hline 11 (Savoie) & $1.40(1.29-1.51)$ & $15.1^{* * *}$ \\
\hline Adjusted $\mathrm{R}^{2}$ & & 0.20 \\
\hline
\end{tabular}

${ }^{1}$ Reference $=$ for the considered variable, class used as reference; removed $=$ the variable was removed from the model because it was not significant.

${ }^{2}$ The $95 \%$ CI is given in parentheses.

${ }^{3}$ The results were expressed in mortality change (\%). For instance, having a beef herd in addition to a dairy herd (farm type = dairy and beef) was associated with a mortality rate change of $-1.1 \%$, compared with not having a beef herd in addition to a dairy herd (farm type = dairy; reference class).

${ }^{4}$ For an increase in herd size of 10 cow-years; the number of cow-years equaled the sum of all the days and all the cows divided by 365 .

${ }^{5}$ For an increase of $10 \%$.

${ }^{*} P<0.05 ;{ }^{* *} P<0.01 ;{ }^{* * *} P<0.001$.

(Charolais, Limousine, and Blonde d'Aquitaine). As a partial conclusion, the presence of a beef herd is associated with decreased dairy calf mortality, probably through better technical skills and know-how in newborn calf management.

The increased mortality of dairy beef-crossed calves on farms with a beef herd cannot be explained without further research. Mortality in heifers $>1$ mo old (Table
6) as well as in cows (Raboisson et al., 2011) is also positively associated with having a beef or a fattening herd in addition to the dairy herd. Maybe having 2 herds leads to difficulties in farm management (dispersal of daily activities). The fact that mortality and having a beef herd were positively or negatively associated, depending on the category of animal, is in accordance with the lower risk of calf mortality noted in areas with 
Table 6. Mortality of dairy heifers from 1-mo-old to the first calving ${ }^{1}$

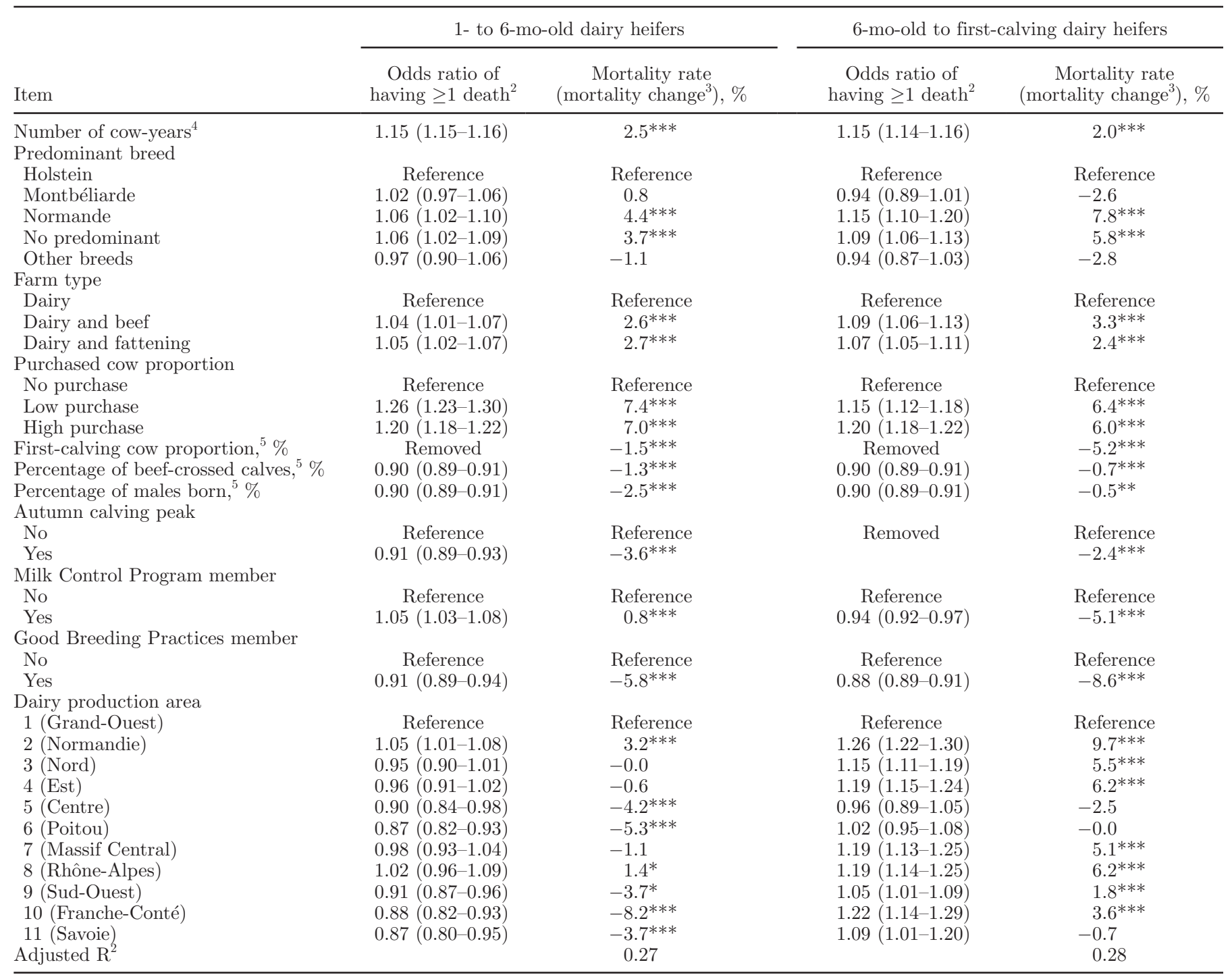

${ }^{1}$ Reference $=$ for the considered variable, class used as reference; removed $=$ the variable was removed from the model because it was not significant.

${ }^{2}$ The $95 \%$ CI is given in parentheses.

${ }^{3}$ The results were expressed in mortality change (\%). For instance, having a beef herd in addition to a dairy herd (farm type $=$ dairy and beef) was associated with a mortality rate change of +2.6 and $+3.3 \%$, for 1 - to 6-mo-old dairy heifers and 6-mo-old to first-calving dairy heifers, respectively, compared with not having a beef herd in addition to a dairy herd (farm type = dairy; reference class).

${ }^{4}$ For an increase in herd size of 10 cow-years; the number of cow-years equaled the sum of all the days and all the cows divided by 365 .

${ }^{5}$ For an increase of $10 \%$.

${ }^{*} P<0.05 ;{ }^{* *} P<0.01 ;{ }^{* * *} P<0.001$.

a history of beef production [for instance, areas 7 (Massif Central) and 8 (Rhône-Alpes); Sarzeaud et al., 2008]. It is also in accordance with the lowest heifer mortality reported for area 1 (Grand-Ouest), with dairy production as the main production (Table 7).

The second main finding in the present study was the negative association between the proportion of males born and the mortality of heifers for all heifer classes of age. This association was positive for the other catego- ries of animals (Tables 3 to 6 ). Testing this association is not irrational, as suggested by the standard deviations of the proportion of males born (Table 1). Importantly, the decrease in mortality with the increase in the proportion of males born was observed not only for young heifers but also, for a given year, for older heifers up to the first calving (i.e., born in the previous year). The decrease in heifer mortality with an increase in the proportion of males born cannot be distinguished here 
Table 7. Associations between mortality of breeds and French areas ${ }^{1}$

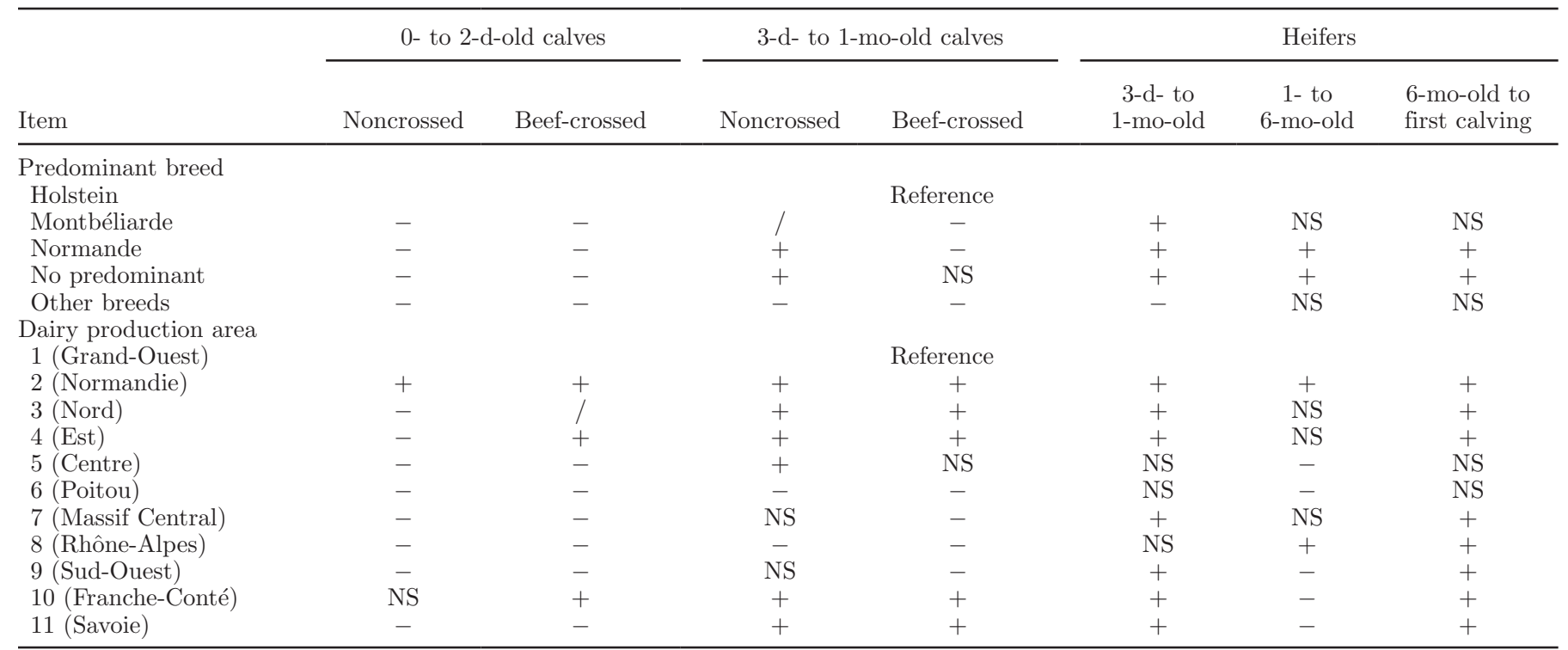

${ }^{1}$ Results are a summary of associations between mortality and breed or dairy production area detailed in Tables 3 to 6 . Results refer to the variable reference class (Holstein or area 1) $+=$ positive significant association in 2005 and 2006; $-=$ negative significant association in 2005 and $2006 ; /$ = significant positive or negative association, depending on the year.

from the increase in heifer mortality with the increase in the proportion of females born. But the fact that older heifers were also affected by the proportion of males born in a given year shows that an increase in the proportion of males born (or decrease in proportion of females born) is associated with changes in heifer management, whatever their age class considered. Farmers cannot control the male:female ratio, except in the few herds using sexed gametes. It demonstrates an adaptation of farmers' management of heifers when the heifer birth proportion changes. The fact that heifer mortality increases with the proportion of females born also demonstrates that farmers do not systematically implement the management practices leading to low calf and heifer mortality even though they have the technical capacities to achieve low mortality. They only implement the necessary measures under certain conditions. To our knowledge, the association between heifer mortality (all classes of age) and the proportion of females to males born for a given year has not been demonstrated so far.

The main limit of the present work is that the evaluation of farmer characteristics (know-how for difficult calving or nursing) was indirect and based on data set variables. It is likely that questionnaires and surveys would have provided more precise data, but using such methods would have reduced the number of observations and the diversity of situations involved and would have increased the subjectivity of the results. In contrast, with the present method, the risk factors could be compared between different populations (newborn calves, calves, heifers, and cows) under the same field conditions.

\section{CONCLUSIONS}

The present study shows first that the presence of a beef herd in addition to a dairy herd within a farm is associated with decreased dairy calf mortality. It also demonstrates that farmers achieve low heifer mortality when the proportion of heifers born decreases. These determinants of dairy calf and heifer mortality are of great importance for farmer advisors, the dairy industry, and political decision makers.

\section{ACKNOWLEDGMENTS}

The authors thank Pascal Deriu (Information Systems, French Ministry of Agriculture, Paris, France) for data provision) and Roland Chartier and Benoit Garcia (INRA, Toulouse, France) for data management support.

\section{REFERENCES}

Beam, A. L., J. E. Lombard, C. A. Kopral, L. P. Garber, A. L. Winter, J. A. Hicks, and J. L. Schlater. 2009. Prevalence of failure of passive transfer of immunity in newborn heifer calves and associated management practices on US dairy operations. J. Dairy Sci. 92:3973-3980.

Berglund, B., L. Steinbock, and M. Elvander. 2003. Causes of stillbirth and time of death in Swedish Holstein calves examined post mortem. Acta Vet. Scand. 44:111-120. 
Bicalho, R. C., K. N. Galvão, S. H. Cheong, R. O. Gilbert, L. D. Warnick, and C. L. Guard. 2007. Effect of stillbirths on dam survival and reproduction performance in Holstein dairy cows. J. Dairy Sci. 90:2797-2803.

Donovan, G. A., I. R. Dohoo, D. M. Montgomery, and F. L. Bennett. 1998. Associations between passive immunity and morbidity and mortality in dairy heifers in Florida, USA. Prev. Vet. Med. 34:31-46.

Gulliksen, S. M., K. I. Lie, T. Løken, and O. Østerås. 2009. Calf mortality in Norwegian dairy herds. J. Dairy Sci. 92:2782-2795.

Gundelach, Y., K. Essmeyer, M. K. Teltscher, and M. Hoedemaker. 2009. Risk factors for perinatal mortality in dairy cattle: Cow and foetal factors, calving process. Theriogenology 71:901-909.

Johanson, J. M., P. J. Berger, S. Tsuruta, and I. Misztal. 2011. A Bayesian threshold-linear model evaluation of perinatal mortality, dystocia, birth weight, and gestation length in a Holstein herd. J. Dairy Sci. 94:450-460.

Linden, T. C., R. C. Bicalho, and D. V. Nydam. 2009. Calf birth weight and its association with calf and cow survivability, disease incidence, reproductive performance, and milk production. J. Dairy Sci. 92:2580-2588.

Lombard, J. E., F. B. Garry, S. M. Tomlinson, and L. P. Garber. 2007. Impacts of dystocia on health and survival of dairy calves. J. Dairy Sci. 90:1751-1760.

Meyer, C. L., P. J. Berger, and K. J. Koehler. 2000. Interactions among factors affecting stillbirths in Holstein cattle in the United States. J. Dairy Sci. 83:2657-2663.

Meyer, C. L., P. J. Berger, K. J. Koehler, J. R. Thompson, and C. G. Sattler. 2001. Phenotypic trends in incidence of stillbirth for Holsteins in the United States. J. Dairy Sci. 84:515-523.

Ortiz-Pelaez, A., D. G. Pritchard, D. U. Pfeiffer, E. Jones, P. Honeyman, and J. J. Mawdsley. 2008. Calf mortality as a welfare indicator on British cattle farms. Vet. J. 176:177-181.

Raboisson, D., E. Cahuzac, P. Sans, and G. Allaire. 2011. Herd-level and contextual factors influencing dairy cow mortality in France in 2005 and 2006. J. Dairy Sci. 94:1790-1803.

Raboisson, D., F. Delor, E. Cahuzac, C. Gendre, P. Sans, and G. Allaire. 2013. Perinatal, neonatal, and rearing period mortality of dairy calves and replacement heifers in France. J. Dairy Sci. 96:2913-2924.

Rea, D. E., J. W. Tyler, D. D. Hancock, T. E. Besser, L. Wilson, D. S. Krytenberg, and S. G. Sanders. 1996. Prediction of calf mortality by use of tests for passive transfer of colostral immunoglobulin. J. Am. Vet. Med. Assoc. 208:2047-2049.
Rouquette, J. L., and A. Pflimlin. 1995. Major Livestock production regions: A zoning proposal for France. In Symposium International sur la Nutrition des Herbovires (SINH), Clermont-Ferrand, France. INRA, Paris, France.

Sarzeaud, P., F. Bécherel, and C. Perrot. 2008. A classification of European beef farming systems. Pages $23-31$ in EU beef farming systems and CAP regulations. P. Sarzeaud, ed. EAAP Technical series, Paris, France.

Silva del Río, N., S. Stewart, P. Rapnicki, Y. M. Chang, and P. M. Fricke. 2007. An observational analysis of twin births, calf sex ratio, and calf mortality in Holstein dairy cattle. J. Dairy Sci. 90:1255-1264.

Steinbock, L., A. Näsholm, B. Berglund, K. Johansson, and J. Philipsson. 2003. Genetic effects on stillbirth and calving difficulty in Swedish Holsteins at first and second calving. J. Dairy Sci. 86:2228-2235.

Stull, C. L., L. L. McV. Messam, C. A. Collar, N. G. Peterson, A. R. Castillo, B. A. Reed, K. L. Andersen, and W. R. VerBoort. 2008. Precipitation and temperature effects on mortality and lactation parameters of dairy cattle in California. J. Dairy Sci. 91:45794591.

Tyler, J. W., D. D. Hancock, J. G. Thorne, C. C. Gay, and J. M. Gay. 1999. Partitioning the mortality risk associated with inadequate passive transfer of colostral immunoglobulins in dairy calves. J. Vet. Intern. Med. 13:335-337.

Tyler, J. W., D. D. Hancock, S. E. Wiksie, S. L. Holler, J. M. Gay, and C. C. Gay. 1998. Use of serum protein concentration to predict mortality in mixed-source dairy replacement heifers. J. Vet. Intern. Med. 12:79-83.

UCLA (University of California, Los Angeles). 2012. Introduction to R. UCLA: Academic Technology Services, Statistical Consulting Group. Accessed Feb. 20, 2012. http://www.ats.ucla.edu/stat/ mult_pkg/faq/general/log_transformed_regres sion.htm.

Vaarst, M., and J. T. Sørensen. 2009. Danish dairy farmers' perceptions and attitudes related to calf-management in situations of high versus no calf mortality. Prev. Vet. Med. 89:128-133.

Wells, S. J., D. A. Dargatz, and S. L. Ott. 1996. Factors associated with mortality to 21 days of life in dairy heifers in the United States. Prev. Vet. Med. 29:9-19.

Wells, S. J., L. P. Garber, and G. W. Hill. 1997. Health status of preweaned dairy heifers in the United States. Prev. Vet. Med. 29:185-199. 